\title{
Comparison of Enlightenments on Contemporary Eco-city Construction---between Ecological Values in Traditional Chinese Culture and the Western Ecological Ethics
}

\author{
Wang Jiequan, Peng Mingsheng \\ Yunnan University, China Scholarship Council supports projects for young teachers training abroad
}

Keywords: the traditional Chinese culture, ecological values, ecological cities, the modern ecological ethics and the ecological city management.

\begin{abstract}
The ecological ethic values, which determine the extent of people's demand for natural resources, the natural resource extraction and distribution, have a great impact on people's behaviors and bring utilization and alteration to our natural environment as well. Objectively speaking, current ecological problems were caused by human beings' production and activities which were closely related with the economy and social development. But if we have a deeper exploration, it may be found that the values were the source of the problem. From micro perspective, values influenced people's needs, needs influenced behaviors and behaviors will affect the environment; while from macro perspective, it influences the social institutions and ways of production.
\end{abstract}

The ecological values began to exert an influence on people's behaviors since ancient times in the traditional Chinese culture, which, however, haven't formed an institution. On contrary, the newly-born western ecological ethics have generated many theories and some related organizations and institutions. It played an increasingly important role in protecting the ecological environment of cities. The development of ecological cities weighs heavily in Chinese cities. In order to tap the potential of our limited resources, it is necessary for us to re-explore and reexamine the basic values which is easily ignored but have an enormous impact on the environmental behaviors. If we combine the traditional ecological values with the modern management system of ecological cities in china to guide people's life and production, the power of this combination will have a huge impact when applied to the planning and construction of eco-cities. This paper is not only centered on the ecological values of the traditional Chinese culture, but also has an insightful comparison with Europe's ecological ethics and its social system. The final purpose is to work out a solution to the nowadays urban ecological problems by comparing the concrete situation of east and west and by looking back in history and looking forward to the future.

If we compare the eco-building as one of the elements in ecological cities, the eco-city planning is the overall technical strategy; the management of eco-city is the guarantee for urban ecology and the human's behaviors is the contributing factor to the ecological environment which means the ecological ethics have a direct impact on people's behaviors. Such ecological ethics affect people's behaviors from the narrow sense and have an implication on social system and productivity from the broad sense. That is to say, the eco-ethics was the fundamental guarantee of eco-cities, which will instruct people's production and activities to lessen the influence on the natural environment. The urban eco-management, the design of eco-buildings and the plan of eco-cities based on the principle of respecting life and protecting our environment will last for a long time.

Confucianism, Taoism and Buddhism all advocated the principal of "harmony between human beings and nature", which is, pursuing the co-habitation between human and nature. The principal was best explained in the minority groups whose religious beliefs were worship and thanksgiving to the nature. Confucianist, which centered on human virtues and started form kindheartedness and virtues, finally classified the nature into the moral community. The supporters of Confucianism will eventually achieve the state of "the people who are kindhearted and moral will integrated with the universe as a whole” by being filial to parents and loving the people and things around him. Taoist, 
which centered on non-interference and taking naturalism as its value orientation, advocated innocence and satisfaction in order to achieve the state of "common happiness between heaven and man". The Chinese Buddhism developed an inner world of poetic quietness by shifting the state from selfishness to kindheartedness. Confucian wisdom was humanistic with direct access to the realm of heaven and earth while the ecological wisdoms of Taoist and Buddhist were beyond humanity but closely related with the real life. The minority groups got a lot of experiences and lessons during their long-term production and activities for they've been having their respect and worship to the nature. However, the wisdoms were reflected in their traditional customs or demonstrated in the design of villages, architecture or landscape. The transition from the western eco-ethics to the environmental management and protection system provided ideas and methods to the construction of eco-city.

\section{The Traditional Chinese Ecological Values}

Confucius firstly put forward the idea of "The benevolent loves others." in his masterpiece The Analects while he also attached great importance to kindheartedness and morality. Man should not confine themselves into their survival and reproduction and treat them as their highest universal values and the only goal, nor deprive the life and living conditions of other beings to meet their own needs. Therefore, the Confucian moral community was also extended to the whole nature, giving common meaning to kindheartedness and morality. As recorded in The Analects, "fishing with pole instead of net and leave a way to the returning birds" which means that Confucius fished only with fishing instead of a net and objected to killing the returning birds. Confucius advocated that we should consider all beings including birds, beasts, grass and trees as an equal part of our life. Mencius also said: "do not miss farming and people will be abundant with food; do not fishing frequently and fish will be on our daily table; deforest at a regular time and people will be rich with woods". It is obvious that Confucian not only considers kindheartedness and morality as human nature but also expands into the whole universe, making it a universal value.

Mencius has said that "gentlemen love all beings but not benevolent to them, gentlemen love people but not keen to them". At this point, "love" was a kind of emotion to the whole universe; "kindheartedness" was a kind of sympathy to human beings and "benevolence" mainly referred to the expression of people's affection for their relatives although "love", "kindheartedness" and "benevolence" all belong to morality. There were differences in the expressive way and orientation in the above three virtues. However, we can even see the logic relations in it. As what The Mean of Doctrine said, "You can create wonders if you have tried your best, you can praise heaven if you create wonders and you are integrated with the universe as a whole if you've praised the heaven and earth". We can say that being benevolent to relatives, being kindhearted to people and loving all things in the universe constitute the basic order and the inner structure of the Confucian eco-ethics. Just as The Mean of Doctrine said, "the whole universe will be well-managing if things could be considered as mean", which means the optimized order in the world, a kind of ecological harmony.

Zhang Zai said his book Ximing in the song dynasty that the whole universe was a big family in which the heaven and the earth acted as the parents and people were the children. Human beings, as members of the family, should take their responsibility. Ximing recognized the position of man in the universe and thus believed that the human beings as well as all beings in the universe are the siblings of us.

Lao Zi (philosopher in the Spring and Autumn Period, founder of Taoism) said that all things in the universe are all self-governing. The so-called "Tao" was the origin and order of life, which served as the energy of the ever-lasting universe. The word "nature" means the original state of the universe. Following the nature was doing things according to its principle. Opposing the nature was actually the wrongdoings to our universe. Lao Zi holds that "the natural inaction" is the state of Tao. Instead of being idle, man should respect the nature and follow the natural principal.

Chuang-Tzu also agreed that Tao has the nature of non-interference. Man should conform to the nature of all things since everything originate form Tao. From the fables like "duke breeds bird" and "the story of bole and swift horse", Chuang-Tzu told us that man should treat all things with 
non-interference for things were born to be self-satisfying. If man impose their will to the beings and try to change the natural state of the nature with the help of their knowledge and techniques, they will damage our universe to some extent..

Lao $\mathrm{Zi}$ warned man to utilize the resources in a rational way and restrain their desire. He once said that disasters come from endless desire and never-ending satisfaction with our current belongs. Men who are often satisfied with himself are happy all the time. As early as 2500 years ago, Lao $\mathrm{Zi}$, the founder of Taoism, realized that it is the endless desire of man that the relationship between man and nature was broken up. As a group of beings of the whole universe, men should not spare any effort to meet their own needs at the expense of sacrificing other groups of beings. Therefore, men should restrain their desire if they want to declare a war against pollution for survival.

What the Taoist called "the harmony between heaven and man" was actually a pursuit ecological beauty. Chuang Tzu said that the world was silent with beauty and the four seasons keeps quiet with laws and the whole universe keeps silent with justifications. The Taoist aesthetic attitude toward the nature was not all passive and negative. Instead, it can be regarded as a happy and positive attitude towards life.

Buddhism is a religion which has respects for life and nature. Such concept was disseminated and practiced through its teachings and commandments at the early stage of Buddhism. Buddhists believe that life and the universe all originate from "Yuan", a mythical thing that cannot be explained with science. However, "Yuan" was the views of Buddhist toward the universe. From nature's point of view, the Chinese Buddhism "selfishness" considers all things as equals and opposes the position of subject. Finally, it eradicates people's superiority to other beings in the whole universe. Such thinking emphasize that all things in the universe including man, animals and plants were interrelated and interactional. All things in the universe play the role of both subject and object. The ecological values of Zen are that men are an equal part of the natural environment. There was a very popular Buddhist poem in Nan song dynasty which goes that "There are flowers in the spring, cooling breeze in summer, month in autumn and snow in winter, the timing could not be better if we had no business in the heart."

The essence of Zen is a philosophy of poem and soul. The wisdom of Zen is profound which centered on cultivating our mind and advocated "the harmony between heaven and man". Zen believed that the reality of the world and the other side of the pure land, subject and object, nature and I can integrate as one, thus radically restored the equal relationship between man and nature.

Many minorities hold their great worship and awe to nature for they believed that everything has a soul and then treat the nature as holy land. Nature plays the role of holy in the minority groups for their lacking of scientific knowledge. They deify the nature and see it as the mysterious spirit of personification. For example, "the heaven god" who was widely acknowledged by people, "the earth god" who governed the growth of the whole universe, "the water god" and "mountain god" where the holy souls rest in. it is very common in some minority groups that people are holding sacrificial ceremony to the holy soul. A lot of areas inhabited by ethnic minorities formed a beautiful natural village because of the awe and fear for the mountains.

Tibetans believe in Tibetan Buddhism which show great respect to the nature for they believe mountains, especially the snow-capped mountains are gods. They are not allowed to climb or conquer the mountains, nor mine on earth which is considered an offence to the earth god. Water, like the milk in Tibetans' eyes, also cannot be polluted for it has nourished people. When Tibetans came to temple for blessing, they will firstly pray for the environment and all people in the world and then for himself. From point of Tibetans, the environment is of top priority for it is the basis of all things. Anyone who offends the nature and the surrounding environment must be punished.

The religious belief of Miao nationality is worshipping the nature and their ancestor. Besides, they paid more attention to the mountain God, the tree God, the hunting God, the rain God, the fire God and many other God of deism. The native religion of Bai nationality is the Bishop which was essentially a primitive worship of all religions. The word "bishop" means "the border lord" and called "ngel zex (literally means my lord)" in the native language. People of Naxi nationality worship Dongbaism, believing that people were indebted since their birth. They believed that men 
will back to nature when they died. Yi people believe in the immorality of the soul.

The Miao nationality stationed in Leigong Mountain must protect the small tress when deforesting. The trees at the top of the mountain were not allowed to be cut, nor the fertile "female trees" for they were considered as the basis of reproduction. De'ang nationality insisted that trees were the guarantee of water. The Miao people of Congjiang in GuiZhou province will plant a tree on a place where one was buried when he or she died. The Dai nationality in Yunnan province has the custom of "the redeeming tree", that is, you need to plant another ten trees if you cut a tree.

\section{The Western Ecological Ethics}

The modern ecological ethics is produced in the natural relationship of people's reflection. The eco-ethics is a series of morality standards involved in the relationship between man and the surrounding environment including the animals, environment and the nature. Generally speaking, the eco-ethics is the relationship and the principals formed in human beings' activities. In the modern ecological ethics, every life has the right of survival. In the 1970s, the eco-ethic has emerged from a value into a social system.

The beginning of eco-ethics can date back to the early 19th century when the philosopher of the Great Britain named Jeremy Bentham firstly extended the range of morality to animals. Jeremy Bentham believed that the ability of feeling happiness and bitterness was the fundamental characteristics of obtaining the equal right. In 1915, the famous thinker Albert Schweitzer (1875-1965) put forward the view of "Reverence for life" which was firstly stated in 1919.In 1923, Albert Schweitzer shed light on his thought "reverence for life" in his book The Philosophy of Civilization: Culture and Ethics. In 1952, Albert Schweitzer was awarded with the Nobel Peace Prize for his theory of "reverence for life". Reverence for Life is of epoch-making significance to the development of people's thinking and the progress of civilization. The theory of reverence for life, with the integration of life as the logical starting point of the thought, pointed out that the human's existence was not isolated but closely relied on the harmony between other beings and the whole world. The theory denied the value order of life and expanded the human ethical care to all creatures and the whole world. Furthermore, it advocates the mutual equality and mutual respect to all creatures and men should establish a close rapport with the whole universe. Albert Schweitzer expected that men might have a deeper awareness in the universe. He wrote his book The Philosophy of Civilization, True philosophy must start from the most immediate and comprehensive fact of consciousness: 'I am life that wants to live, in the midst of life that wants to live'.

The forerunner of ecological literature, the author of A Sand County Almanac named Aldo Leopold insisted that the basis of ethics was "the reverence for life" when he enlightened form works of Albert Schweitzer. His views of earth ethics and ecological integration believed that all species on earth are all equal but inferior to the earth. Any behavior was right when it is beneficial to the protection of the harmony and beauty or it was wrong.

The word "The deep ecology" was firstly put forward by a Norway philosopher Arne Næss during a seminar on the further development of the third world in 1973. It was later developed into another environmental philosophy with the efforts of Bill Deval, George Sessions and Fox. Deep ecology, with the non-human-centered perspective, re-evaluates the value of all creatures in the world, breaking the long-standing values of human's life. Deep ecology believe that in order to understand, manage and solve ecological problems, it is necessary to taking the men an nature as a whole form the perspective of the entire ecosystem.

The deep ecologists insisted on asking deeper philosophical questions, exploring why and how people disturb the balance of ecosystem. Deep ecology demonstrates a more comprehensive view on ecosystem and searched for an explanation on how different parts of ecosystem constitute the whole system. The aim of deep ecology is to criticize the wrongdoings of modern industrialized society and find out the real cause for the purpose of finding the real value of human life and the rational construction of modern society. Deep ecology advocates, "we should have the minimum impact on other substances and earth" and "pursuing abundance with the simple lifestyle".

Eco-socialism, also known as eco-Marxism, was a new thought and a school formed in the 
second half of the $20^{\text {th }}$ century.

In the early stage, Herbert Marcuse claimed that we should define "the natural evolution" according to Marx's "possession of humanity", that is in accordance with man's natural thought of possession. In other words, we were determined to carry out a structural revolution and a natural revolution from changing their lifestyle, thinking patterns, physiological types and physiological mechanism. However, the purpose of the revolution, not to lift people out of poverty or for the greater material comfort but to realized the real nature and overcome all kinds of alienation, was finally free the nature and allow men to occupy the nature in a human way.

In The Limits to Satisfaction published in 1976, William Leiss put forward his eco-socialist idea explaining the ecological crisis and the way out of the crisis. He believed that the production by capitalist for the purpose of profit will lead to the alienation of people and the ecological crisis. In order to tackle the ecological crisis, a new kind of "steady economy" must be implemented to reduce the production capacity of the capitalists and change people's way of consumption.

A professor of sociology Agger Ben includes the ecology, the ecological crisis and "the political ecology" theory into his own fields of study. As he wrote in the political ecology, "there has been a serious ecological crisis such as the depletion of resources like water, clean air and land with the development of the science and technology." Furthermore, the proliferation of population also brought a disaster to our nature and the nuclear pollution was destroying the ecological environment. the only way out of those disasters is to hamper the economic growth, change our lifestyle and limit our consumption. And at the same time, it was of vital importance for us to use the renewable energy and the advanced technology.

The soviet scholars also proposed the idea "social ecology" and as a discipline, they think, it needs not only to realize the interaction of each discipline in natural science, but the interaction of natural science and social science. Only the chemist, economist, socialist, jurist and psychologist united can the environmental problem be solved. With the joint efforts, conceptions like "Biosphere", "Noosphere" and "Co-evolution" are in blossom. "Co-evolution" means that targeted development of human society and oriented effect of "Biosphere": no damage to biosphere, and even boost the biosphere and advance human society.

Representative figures of Eco-socialism (in the 1990's), as European scholars and Left-wing social activist, George Labica, Reiner Grundmann and David pepper .etc. though their ideas are from "Western Marxism", they are significantly different: one is the unity of many realistic activities - ecological activity(or environmental protection activity), it breaks the ivory-tower and metaphysical academic research in Marxism and combines more with practical problems; the other is more attention was paid to human living environment, and it links living environmental issues to political issues.

Eco-ethics is different from the traditional ethics whether in connotation or denotation. Instead of being formulated, the traditional ethics were naturally formed and usually not set down into laws, existing into people's common sense and beliefs. Although traditional ethics also advocate heteronomy, it focuses on self-consciousness and introspection rather than coercion. Due to the complexity and urgency about eco-protection issue, the eco-ethics not only need to be encouraged but also to be forcibly implemented.

The main reason for ecological crisis is that the food chain of ecosystem is damaged, thereby contributing to the difficulties of survival and development for creatures. The history of human development shows that the harmony between human and nature has to be rebuilt in order to ease their relationship. Firstly, we should control population growth to make a balance between population growth and ecological capacity of population on earth. It is calculated that the capacity of holding population on earth can reach 8 billion at most. The world population has reached 7 billion in 2011 and 7.3 billion in 2015. If we had no measures to control, the population would continuously increase and reach to over 9 billion in 2045, which is beyond the ecological population capacity of the earth. Therefore, it is an urgent task for us to control population growth in order to ensure the coordination between human demand and supply of natural reproduction. Secondly, we should seriously confine the behavior of transforming nature into the rule of ecological movement, 
thus coordinating human activities with natural laws. Thirdly, we should control pollutant emissions within self-purification capacity of nature and promote the coordination between pollutant emissions and self-purification capacity of natural ecosystem. Fourthly, we should coordinate between the exploitation of natural resources and the capacity of natural reproduction to leave sufficient room for human's sustainable development. As for the exploitation of renewable resources, we should also stick to the principle that lay equal stress on exploitation and protection, and promote the capacity of natural reproduction to ensure that extinction of species cannot exceed revolution of species; soil erosion cannot exceed soil formation; forest deterioration cannot exceed forest restoration; fish catch cannot exceed regenerative capacity of fishery for having a harmonious relationship between human and nature. Human should put themselves into an ethical position in nature. Only if human can consciously control their ecologically ethical behavior and treat nature in a rational and friendly way can the relationship between human and nature turn to harmony, thus achieving the real value of eco-ethics.

All countries in the world actively strain every sinew to solve ecological problems and should organize conferences and formulate goals and policies beyond nations' boundaries. In 1972, the United Nations held a conference on the human environment in de Gore, Sweden, which set up an independent committee, that is, World Commission on Environment and Development. This committee shouldered the investigation and study task which revaluates the relationship between environment and development. Since the 1980s, some companies in the US and Western Europe have reduced pollution, improved their public images to get the support for commodity management and began to set up their own environmental management patterns in order to respond to the call for sustainable development. In 1992, the Conference on Environment and Development was held in Rio de Janeiro, Brazil. One hundred and eighty-three countries and over seventy international organizations attended this conference in which passed Agenda 21 and other documents. This conference marked the beginning of sustainable development era of global pursuit. In this year, the document, the Protection of the Earth - the Strategy for Sustainable Living was issued which put forward nine principles for sustainable survival. The first principle is that human has and will have the duty to care for other people and other livings. It is an ethical principle and has become importantly spiritual pillar and value orientation for environmental protection. Governmental leaders, scientists and citizens in all countries realized that in order to achieve sustainable development goals, we should have to change strategies of pollutant control in industry and set up a new concept of pollutant prevention (cleaner production) starting from enhancement of environmental management. Therefore, ISO set up ISO/TC207 in June, 1993 which formally implemented the formulation of series of standards on environmental management, regularized environmental behaviors including activities, products, and services in companies and social communities, and supported the work of globally environmental protection. In 2015, national leaders of 195 countries attended climate conference- COP21 in Paris, which made sure the definite goals and measures that the temperature of global warming triggered by human will have to be controlled below 2 degree Celsius and strive to below 1.5 degree Celsius before 2100. Since 2020, the developed countries will provide at least annually 100 billion dollars for improving global warming. 186 countries have submitted detailed plans.

Apart from international conference formulating developmental direction, some activities carried out in communities where eco-ethical concept effectively combined with social systems. For instance, government formulated a series of systems in city parks in Paris and citizens actively involved into planting public green land in city. Apart from formulating standards and systems in ecological plan, ecological architecture design, and management in the city, the ecological behaviors and concepts exert an important role in construction and maintenance for ecological communities in some ecological communities in Europe such as Hammarby Sjöstad (la ville du lac Hammarby) in Sweden ecological community, Clichy-Batignolles in Paris ecological community, Fribourg-en-Brisgau in Germany and le quartier BedZED in London etc.

In order to make ecology have true and reliable protection, Europe has formulated compulsive ecological policies and has set up definite goals combining with eco-ethical concept and productive 
development in society. The policy of ecological protection not only refers to the relationship between individual and social interest, but also advocates social value is superior to individual value. The formulation of definite goals is beneficial for all departments to work with goals in the process of planning and constructing in economy, society, law, psychology.

\section{Comparison on significances of traditional eco-ethics and eco-system to construction of eco-polis}

Since city emerged, humans have retained the admiring and pure spirit pursuits for nature. At ancient times, city construction was geomantic omen oriented, and site selection was on the important basis of landscape pattern. Humans tried every way possible to impose their ideal of combination with nature on their artificial environment and expected some power given from nature, for a perennial favorable weather and environment amenity. Geomantic theory affects the site selection and development of a city.

For example, Xian is the ancient capital of 13 dynasties, located in Guanzhong basin. It is bounded on the south by Qinling Mountains; on the east by Huashan Mountain; on the west by Mount Taibai; on the north by Wei River. A livable city could be seldom seen at Central Plains. On account of the painstaking administration of dictators, the general layout "Eight more rivers around Changan" was even formed in Han-Tang period, therefore, the national power was flourishing. However, with the climate changed, the eight rivers gradually dried up. Even though Xian is yet to be livable, its geomantic omen was lost as before.

The ancient capital "Beijing" is back against the high Yanshan Mountains and Mongolian Plateau, facing the capacious Central plains in china, steady and wide. On the east, Liaodong and Jiaodong Peninsula are in charge of Bohai Bay; on the east, Taihang Mountains is the best defense. Even though Forbidden City controlled by imperial ideology is grand and strictly symmetrical, in which beautiful, natural and vast Beihai and Zhongnanhai could be complementing. And the well-known historical geomancers has programmed and arrangement for its geomantic omen, trying to realize the unity of man and nature.

Kunming, presently the important city for China-Southeast Asia economy growth, which is facing south and sunrise, back against the hill and overlooking the river. On the east of Kunming is Mount Jinma, the southwest is Mount Bijin, embracing on the left and right, that is the geomantic pattern called "Left Tsing long, right White tiger". Qing poet Sun Ran depicted in long couplets: the Dian Lake, five hundred miles, is flushing to me, with clothes open and cap down, I'm excited about the endless waves. Look! The eastern Jinma Mountain seems a horse galloping; the western Bijin Mountain is a phoenix dancing in the air; the northern Snake hill is wriggling and the He Mountain on the north is a white crane hovering... this is the exact unity of city and nature.

In architecture, to revere and worship nature is the absolutely core and prominent component in minorities' eco-ethics, which is reflected on the every segment of building villages and houses has its matched worship ceremony, showing the faiths to surrounding natural environment of all ethnics. Many traditional villages and residential buildings take advantage of topography, thus climate and geographical features create different styles.

In the process of traditional city planning and construction, the people integrate natural landscape into artificial environment, to withstand the increasing isolation between man and nature. "The unity of man and nature", stressed on harmonious unity of natural landscape and man-made cities, adjusting measures to local conditions; "Tao follows nature”, emphasized on the unity of objective condition and law with subjective wishes and ideas.

However, along with the economy growth and city expansion, our city emerged variety of problems: the air and water pollution, since October of 2011, fog and haze weather emerged in Harbin, Beijing and Shanghai .etc. which is a repeat just as severe as in Meuse river Valley in 1930, at Los Angeles in 1943 and London in 1952. The beautiful Dian Lake of Kunming, water pollution has become an acute problem of eco-polis, which influenced the city image. Rethinking our acts and city construction, the reason may be that we didn't attach importance to the ecological intelligence, but excessively extorted resources from nature. 
China is on the stage of rapid urbanization, from $17.9 \%$ in 1978 to $56.1 \%$ in 2015, the ratio of urbanization increase a full percentage point every year, the urban area increase from 7 thousand square kilometers to 49 thousand square kilometers during 1981 to 2014. In the past constructing way, looking up to scale and down efficiency, preferring production to living and valuing matter rather than spirits and culture led to a certain ecological problem. With the development of economy and improvement of living standards, the urban development will turn the orientation to "livable city”, "livability” including low-carbon eco-polis and appreciation of spiritual culture ${ }^{12}$.

Buddhism advocates "little desire and contentment", warning that excessive request would do harm to ourselves and the environment. Under the circumstance man and nature are in harsh opposition, so as to our living environment deteriorating. We can't deny that its root is the undue greed of humans. Confucianism proposes "worship heaven and earth, love all beings”, while human beings live on and multiply, they need to maintain the equal right of the other creatures or species. Taoist Lao Tzu thought "inaction to nature" is Tao's intrinsic state, which is not referring to do nothing or unable to doing, but to respect its nature and ecology, following the laws of nature. The minority has always respected and worshipped nature in daily life and production, so accumulated a lot of constructing and planning experience, which brought some revelation to our acts:

Construction size of a city should adjust to the capacity of resources and environment, thus the production and living of people cannot take too much resource from nature. The city should link with the surrounding natural environment and social economy environment, and maintain the equilibrium of supply and demand, there would be a sustainable development. City, the same as beings, is closely related to the circumjacent areas. City construction is limited and affected by the around natural condition, therefore not only the factors of surrounding soil, geomorphologic landscape and agriculture .etc. but the local history, geography and culture .etc. should be taken into consideration, if considering city and industry, in order to attain the dynamic balance of areas and the city. Eco-polis a compound system relying on natural environment and living on the resource condition, with economy, society and environment coordinating and unifying.

Except the harmony of man and nature, the most important thing is that of man and man. "The best city pattern is to care for and cultivate man”, and all the sites and infrastructure being good for people could benefit ordinary citizens. Eco-polis is also a caring environment, in which encouraging interpersonal communication, reducing the isolation of each other and establishing perfect social service and basic infrastructure to cater the need of matter and spirits. However, some people do not fully respect eco-ethics; they ignore the damage to nature only for individual profit, on condition that policy setting and management controlling could be indispensable.

Traditional eco-ethics has virtually conducted human acts and had an important role on eco-polis construction and development. It is such an environment with respect, regardless of his country, race, gender and age; as a member of this city, he has the right and responsibility for planning the eco-polis on how to construct his own residential environment. Only we lead the human to heartily and spontaneously standardize their acts of ecological production and living, and to combine with eco-city planning and construction, policy setting and management controlling, can we attain the best efficiency of city eco-system, then accomplish living in harmony of man and nature.

\section{Acknowledgment}

Funded by the China Scholarship Council, 20140035002, Key Joint Research Office of the Institute of Architecture, Urban, Planning and Environmental Research, Paris University Science Research Center, Visiting Scholar of the Habitat Environment Research Center (CRH/UMR7218 LAVUE/CNRS), Eco City Study Question.

\section{References}

[1] Department of Philosophy, Fudan University, Laozi Notes, 1977.04

[2] Wang Ziyuan, "The New Analects of Confucius", Heilongjiang People's Publishing House, 1st 
edition, September 1991

[3] Schweitzer, Albert, The Decay and the Restoration of Civilization and Ethics (The Philosophy of Civilization, Vols I \& II of the projected but not completed four-volume work), A. \& C. Black, London 1923. Material from These volumes are rearranged in a modern compilation, The Philosophy of Civilization (Prometheus Books, 1987).

[4] Long Bin, Feng Shui and Urban Construction, Jiangxi Science and Technology Press, 2015,

[5] Næss, Arne. Ecology, community and lifestyle. Cambridge University Press, 1989, pp. 164-65

[6] Jiang Gaochun, Yunnan National Housing Culture, Yunda Publishing House, 1997

[7] Yankel FIJALKOW, (2011), Sociologie des villes, Repère. 